Check for updates

Cite this: RSC Adv., 2019, 9, 16738

\title{
Fabrication of an immunosensor for quantitative detection of breast cancer biomarker UBE2C $\uparrow$
}

\begin{abstract}
V. S. P. K. Sankara Aditya Jayanthi, Asim Bikas Das (D) and Urmila Saxena (D)*
This work reports the design of a new electrochemical impedimetric immunosensor for the direct determination of ubiquitin-conjugating enzymes 2C (UBE2C), a potential diagnostic biomarker for breast cancer. The immunosensor was fabricated by immobilizing the capture anti-UBE2C antibody onto a polyaniline (PANI) modified glassy carbon electrode (GCE) through glutaraldehyde crosslinking. The assembly process of the immunosensor was examined using scanning electron microscopy, cyclic voltammetry, and electrochemical impedance spectroscopy. The fabricated immunosensor enabled the detection of recombinant human UBE2C in the range of $500 \mathrm{pg} \mathrm{mL}^{-1}$ to $5 \mu \mathrm{g} \mathrm{mL}$. The limit of detection and limit of quantification were found to be $7.907 \mathrm{pg} \mathrm{mL}^{-1}$ and $26.356 \mathrm{pg} \mathrm{mL}^{-1}$, respectively. The diagnostic application of the fabricated immunosensor was explored for the analysis of breast cancer cell line MCF-7 cell extract. The immunosensor demonstrated high selectivity for UBE2C. The fabricated immunosensor also exhibited good reproducibility and storage stability.
\end{abstract}

Received 13th December 2018

Accepted 12th May 2019

DOI: $10.1039 / c 8 r a 10245 g$

rsc.li/rsc-advances

previously employed to detect UBE2C in breast cancer.

\section{Introduction}

The ubiquitin-conjugating enzyme 2C (UBE2C) is an oncogene and a critical component in the ubiquitin-proteasome system which regulates the cell cycle. ${ }^{1}$ UBE2C mainly participates in controlling mitotic spindle checkpoint during the progression of the cell cycle. ${ }^{2}$ In association with the ubiquitin-activating enzyme (E1), ubiquitin ligases (E3) and anaphase-promoting complex/cyclosome (APC/C), UBE2C helps in ubiquitination of cyclins which is essential during mitotic exit. ${ }^{1}$ Therefore, overexpression of UBE2C surpasses the mitotic spindle checkpoint resulting in genomic instability, which leads to cancer. ${ }^{3}$ Aberrantly high expression of UBE2C is observed in various human malignancies such as astrocytic carcinogenesis, ${ }^{4}$ cervical, ${ }^{5}$ colorectal, ${ }^{6}$ hepatocellular, ${ }^{7}$ lung, ${ }^{8}$ ovarian,,${ }^{9}$ prostate, ${ }^{10}$ and also breast cancer. ${ }^{11}$ Particularly, upregulation of UBE2C frequently causes malignant phenotype in breast cancer as observed in previous reports. ${ }^{12-16} \mathrm{We}$ also analyzed the prognostic value of the UBE2C in breast cancer with BreastMark tool. ${ }^{17}$ The survival rate of patients with higher expression of UBE2C was found to be significantly lower $\left(P=1.1102 \times 10^{-16}\right)$ than those with lower expression of UBE2C (Fig. S1 $\dagger$ ). Therefore, it could be an important biomarker for clinical diagnosis of breast cancer. ${ }^{3,18,19}$ Immunohistochemistry, ${ }^{13,15,16}$ western blotting, ${ }^{20}$ and quantitative real-time polymerase chain reaction (QRT$\mathrm{PCR})^{21}$ are some of the molecular techniques which have been

Department of Biotechnology, National Institute of Technology Warangal, Warangal-506004, Telangana, India.E-mail: urmila.saxena@gmail.com; urmila@ nitw.ac.in; Tel: +91-8332969442

$\dagger$ Electronic supplementary information (ESI) available. See DOI: $10.1039 / \mathrm{c} 8 \mathrm{ra10245g}$
However, these techniques are cumbersome, time-consuming, and lack the reusability of expensive reagents, which restricts their commercial use in clinical diagnosis. Detection systems based on immunosensors are particularly attractive due to realtime measurement, cost effectiveness, high selectivity, and sensitivity. Thus far no attempt has been documented to develop an immunosensor for the detection of UBE2C in cancer.

This study demonstrates the development of electrochemical impedance spectroscopy (EIS) based immunosensor for the detection of UBE2C expression in breast cancer cell. Here we have used polyaniline (PANI) as the immobilization support for antibody immobilization on glassy carbon electrode (GCE) surface. The conducting polymer PANI has been widely used to develop various biosensors because of its exceptional features such as excellent stability, biocompatibility and unique electrochemical properties. ${ }^{22}$ We have used recombinant human UBE2C protein expressed in E. coli, as target, and anti-UBE2C antibody as the biorecognition molecule. For evaluating the ability of the developed immunosensor to quantify UBE2C in real samples, breast cancer cell line, MCF-7 cell was used. The fabricated immunosensor showed high performance concerning a wide detection range and a very low detection limit. Moreover, the design strategy developed here can be further used to detect other biomarkers in clinical diagnosis.

\section{Experimental section}

\section{Materials and apparatus}

All chemicals were of reagent grade or better. Aniline, sulphuric acid $\left(\mathrm{H}_{2} \mathrm{SO}_{4}\right)$, potassium ferricyanide $\left(\mathrm{K}_{3} \mathrm{Fe}(\mathrm{CN})_{6}\right.$, 
$99 \%$ ), and potassium ferrocyanide $\left(\mathrm{K}_{4} \mathrm{Fe}(\mathrm{CN})_{6}, 99 \%\right)$ were purchased from Finar. Potassium chloride (KCl), sodium hydroxide $(\mathrm{NaOH})$, sodium chloride $(\mathrm{NaCl})$, glutaraldehyde, potassium dihydrogen phosphate $\left(\mathrm{KH}_{2} \mathrm{PO}_{4}\right)$, disodium hydrogen phosphate $\left(\mathrm{Na}_{2} \mathrm{HPO}_{4} \cdot 7 \mathrm{H}_{2} \mathrm{O}\right)$, and Luria-Bertani (LB) media were purchased from Merck. Absolute ethyl alcohol (99\%), methanol, imidazole, hydrochloric acid ( $\mathrm{HCl})$, isopropyl $\beta$-D-thiogalactoside (IPTG), sodium dodecyl sulfate (SDS), Tris, acrylamide, and ammonium persulphate were purchased from Ameresco, Triton X-100, Tween 20, Dulbecco's modified eagle media (DMEM), 10\% fetal bovine serum (FBS), sodium fluoride were purchased from Himedia. Polyclonal rabbit UBE2C antibody was purchased from Cell Signalling Technology, Inc (product code no. 14234). Goat HRPconjugated anti-rabbit IgG antibody (A6154), bovine serum albumin (BSA), sodium orthovanadate, phenylmethanesulfonylfluoride (PMSF), and 3,3',5,5'-tetramethylbenzidine (TMB) were procured from Sigma-Aldrich. Western blot substrate (Luminol enhancer and peroxidise solution) and $1 \times$ antimycotic antibiotic were procured from Thermoscientific. All solutions were prepared using deionized water. Human breast cancer cell line MCF-7 was procured from NCCS, Pune, India.

All electrochemical measurements (cyclic voltammetry and EIS) were carried out with potentiostat-galvanostat Autolab (Metrohm, India) using a conventional threeelectrode system with saturated $\mathrm{Ag} / \mathrm{AgCl}(3 \mathrm{M} \mathrm{KCl})$ electrode as the reference electrode, platinum electrode as the auxiliary electrode, and GCE or modified GCEs as working electrode. Electrochemical results were analyzed with NOVA software (version 1.11.0). Enzyme linked immunosorbant assay (ELISA) measurements were performed with UV-Vis spectrophotometer with multiplate reader (Multiskan GO, Thermo Fisher Scientific, USA). Scanning electron microscopy (SEM) images of the electrodes at significant steps of electrode modification were obtained using a scanning electron microscope (S-3700N Hitachi, Germany). Before imaging, samples were vacuum dried for $60 \mathrm{~min}$ at $45{ }^{\circ} \mathrm{C}$ followed by gold sputter (Hitachi, E1010) coating.

\section{Expression and purification of UBE2C}

cDNA of UBE2C cloned in pDEST 17 vector with his tag was gifted by Wade Harper; Harvard Medical School, USA. ${ }^{23}$ The stab culture was grown in LB media and plasmid DNA was isolated. Plasmid DNA was transformed into E. coli strain BL21 (DE3) and cells were grown at $37{ }^{\circ} \mathrm{C}$ overnight. Positive clones were confirmed by colony PCR using forward primer sequence (CGTAAAGGAGCTGAGCCGAG) and reverse primer sequence (GCAGCATGTGTGTTCAAGGG). His-tagged UBE2C protein expression was induced with $1.0 \mathrm{mM}$ IPTG for $16 \mathrm{~h}$ at $25{ }^{\circ} \mathrm{C}$ in $E$. coli strain BL21 (DE3). Cells were centrifuged and lysed by sonication in PBS containing $0.1 \%$ Triton X-100 (pH 7.4). Protein purification was carried out with his trap column according to the manufacturer's protocol (GE healthcare). The His-tagged UBE2C proteins were eluted and dialyzed and stored at $-80{ }^{\circ} \mathrm{C}$ until needed.

\section{Culture and maintenance of human cell line}

Human breast cancer cell line MCF-7 was procured from NCCS, Pune, India. The cells were maintained in DMEM containing $10 \%$ FBS and $1 \times$ antimycotic-antibiotic in $5 \% \mathrm{CO}_{2}$ humidified incubator at $37{ }^{\circ} \mathrm{C}$. Subculturing was done by trypsinization procedure after attaining of $80-90 \%$ confluence. Protein was extracted using RIPA (Radioimmunoprecipitation assay) buffer containing $50 \mathrm{mM}$ Tris-Cl (pH 7.5), $50 \mathrm{mM} \mathrm{NaCl,} \mathrm{1 \%} \mathrm{Triton} \mathrm{X-}$ 100, $0.1 \%$ SDS, protease inhibitor (1 mM PMSF), phosphatase inhibitor (50 mM sodium fluoride and $1 \mathrm{mM}$ sodium orthovanadate). The cell lysate was obtained by centrifugation and stored at $-80{ }^{\circ} \mathrm{C}$ for further use.

\section{Western blot}

Expression of recombinant human UBE2C and UBE2C expression in MCF-7 cell line lysate was detected using western blot. Recombinant UBE2C and MCF-7 cell line lysate was loaded in each well in SDS-PAGE with BSA as a standard. Polyclonal rabbit anti-UBE2C antibody of $1: 1000$ dilutions was used to probe the blots. Anti-rabbit HRP conjugated antibody of 1 : 1000 dilutions was used as secondary antibody. Blots were developed using chemiluminescence western blot substrate.

\section{Enzyme linked immuno sorbant assay (ELISA)}

ELISA was also performed to check the binding of purified protein and its corresponding antibody. Different concentrations of recombinant UBE2C protein $\left(0.0005 \mu \mathrm{g} \mathrm{mL}{ }^{-1}\right.$ to $5 \mu \mathrm{g}$ $\mathrm{mL}^{-1}$ ) in $0.1 \mathrm{M}$ phosphate buffer saline (PBS) (pH 7.4) solution were added to 96 well plates and incubated for overnight at room temperature in humidified condition. 3\% BSA was added to each well to block the unbound sites and incubated for $1 \mathrm{~h}$ at room temperature. The plate was washed with PBS containing $0.1 \%(\mathrm{v} / \mathrm{v})$ Tween 20. Polyclonal rabbit UBE2C antibody of $1: 1000$ dilution was added to each well and incubated for $2 \mathrm{~h}$ at room temperature. After washing, anti-rabbit HRP conjugated secondary antibody of 1 : 1000 dilution was added to each well followed by incubation at room temperature for $1 \mathrm{~h}$. The plate was washed thrice with PBS (0.1 M, pH 7.4) containing $0.1 \%$ Tween 20 and ELISA substrate, i.e., TMB was added to wells. $2 \mathrm{M}$ $\mathrm{H}_{2} \mathrm{SO}_{4}$ was used as stop solution. OD was measured at $370 \mathrm{~nm}$.

\section{Fabrication of immunosensor}

For the fabrication of the immunosensor, GCE was first polished with alumina slurry powder of $0.05 \mu \mathrm{m}$ to obtain mirror finished surface and then rinsed by sonication with deionized sterile water and ethanol for $10 \mathrm{~min}$. The cleaned GCE surface was modified with PANI using cyclic voltammetry (CV). First, the GCE was dipped in a solution of $0.1 \mathrm{M}$ aniline, and $0.5 \mathrm{M}$ $\mathrm{H}_{2} \mathrm{SO}_{4}$ and $\mathrm{CV}$ was performed in a potential range of $0-1 \mathrm{~V}$ for ten cycles with a scan rate of $100 \mathrm{mV} \mathrm{s}^{-1}$. The PANI modified GCE (GCE/PANI) was incubated with $4 \%$ glutaraldehyde at room temperature for $3 \mathrm{~h}$ for the crosslinking of PANI. The electrode was thoroughly washed with sterile deionized water to remove any loosely bound glutaraldehyde. Subsequently, the polyclonal rabbit UBE2C antibody was immobilized on the 
glutaraldehyde modified electrode (GCE/PANI/GLU) by dropcasting $10 \mu \mathrm{l}$ of the antibody $\left(3 \mu \mathrm{g} \mathrm{mL}^{-1}\right)$ on the electrode surface and incubating for $4 \mathrm{~h}$ at room temperature. The surface of the antibody-modified electrode (GCE/PANI/GLU/UBE2C-Ab) was rinsed with sterile deionized water and 0.1 M PBS buffer (pH 7.4) repeatedly to remove unbound antibody from the surface. Finally, to circumvent any nonspecific response, the electrode was blocked with $5 \mu$ l of BSA $(0.1 \%)$ to obtain the final immunosensor (GCE/PANI/GLU/UBE2C-Ab/BSA). The immunosensor was stored at $4{ }^{\circ} \mathrm{C}$ when not in use.

\section{Electrochemical measurements}

$\mathrm{CV}$ and EIS measurements were carried out in an electrochemical cell containing $0.1 \mathrm{M}$ PBS (pH 7.4) with $5.0 \mathrm{mM}$ $\left[\mathrm{K}_{3} \mathrm{Fe}(\mathrm{CN})_{6} / \mathrm{K}_{4} \mathrm{Fe}(\mathrm{CN})_{6}\right]$ and $0.1 \mathrm{M} \mathrm{KCl}$. $\mathrm{CV}$ was performed in a potential range of -1.0 to $1.0 \mathrm{~V}$ with a scan rate of $100 \mathrm{mV} \mathrm{s}^{-1}$. For EIS measurements, an alternating wave of $10 \mathrm{mV}$ amplitude was applied. Impedance spectra were taken in the frequency range between 10000 and $0.05 \mathrm{~Hz}$. The impedance values were fitted to Randles equivalent circuit simulation via NOVA software (Autolab), and results have corresponded to the Randles model.

\section{Results and discussion}

\section{Expression, purification and characterization of human recombinant UBE2C protein}

The pDEST-UBE2C plasmid DNA was isolated and transformed into competent cells of BL21 (DE3). Positive colonies were selected from the transformation plate which was confirmed by colony PCR. Expression and purification were carried out to obtain recombinant UBE2C protein which was resolved by SDSPAGE as shown in Fig. 1A. The molecular weight of the recombinant UBE2C protein was estimated to be around 25 $\mathrm{kDa}$. The purified UBE2C protein was determined with Bradford assay using BSA as standard ${ }^{24}$ and found to be about $225 \mu \mathrm{g}$ $\mathrm{mL}^{-1}$ approximately. The purified recombinant UBE2C was detected with western blotting with polyclonal rabbit UBE2C antibody (Fig. 1B). Western blotting of the MCF-7 cell lysate was also carried out to confirm the expression of UBE2C (Fig. 1C).

To evaluate the specificity of the purified UBE2C and to assess its capability to be detected with polyclonal rabbit antiUBE2C antibody, indirect ELISA was performed. Different concentrations of UBE2C ranging from $0.0005-5 \mu \mathrm{g} \mathrm{mL}{ }^{-1}$ and $1: 1000$ dilution of polyclonal rabbit UBE2C antibody was taken for this study. The results presented in Fig. 1D demonstrates that the ELISA signal was slightly weak with low concentrations of UBE2C (0.0005-0.005 $\left.\mu \mathrm{g} \mathrm{mL}^{-1}\right)$, but increased linearly from $0.05-5 \mu \mathrm{g} \mathrm{mL} \mathrm{m}^{-1}$ of UBE2C. The performance of ELISA was found to be very low for small concentrations of UBE2C. The limit of detection (LOD) and the limit of quantification (LOQ) of the ELISA were calculated from the expression LOD $=(3 \times \mathrm{SD}) / m$ and $\mathrm{LOQ}=(10 \times \mathrm{SD}) / m$ (where SD is the estimated standard deviation from the points used to construct the calibration curve and $m$, its slope). The LOD and LOQ were determined to be $0.568 \mu \mathrm{g} \mathrm{mL} L^{-1}$ and $1.859 \mu \mathrm{g} \mathrm{mL}^{-1}$ respectively. Indirect
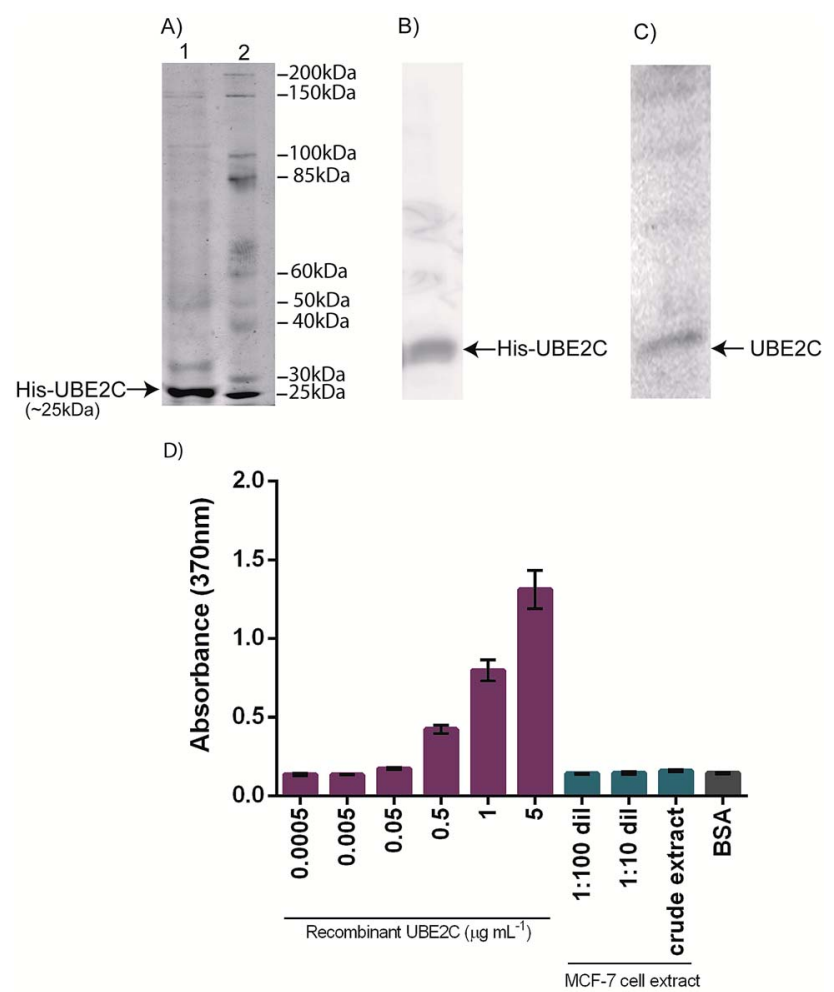

Fig. 1 Purification and characterization of recombinant human UBE2C expressed in E. coli BL21 (DE3). (A) SDS-PAGE showing purified his-tag UBE2C protein in lane 1 and protein molecular weight marker in lane 2. (B) Western blot of purified his-UBE2C expressed in E. coli BL21 (DE3), and (C) western blot of UBE2C expressed in MCF-7 cell lysate. In western blots, proteins were detected with polyclonal rabbit UBE2C antibody followed by anti-rabbit HRP conjugated antibody. (D) Indirect ELISA with 1 : 1000 dilution of polyclonal rabbit UBE2C antibody. Bar diagram represents mean absorption value (at $370 \mathrm{~nm}$ ) value. Error bars represent the standard deviations.

ELISA was also performed with $1: 1000$ dilution of polyclonal rabbit UBE2C antibody and different dilutions of MCF-7 cell extract (1:100 dilution, $1: 10$ dilution and crude extract) to quantify the expressed UBE2C protein in the MCF-7 cell extract. The signals obtained were very low and the ELISA assay was not sufficiently sensitive to detect and discriminate different concentrations of UBE2C at the lower levels. Therefore, electrochemical impedance-based immunosensor was developed to improve the detection range and limits to address clinical needs.

\section{Optimization of the immunosensor fabrication}

The glutaraldehyde concentration used for crosslinking and amount of UBE2C antibody loaded on electrode surface were optimized for fabrication of UBE2C immunosensor. The effect of glutaraldehyde concentration was investigated by incubating PANI modified electrodes (GCE/PANI) with different levels of glutaraldehyde $(1 \%, 2.5 \%, 4 \%$, and $5 \%)$ at room temperature for $3 \mathrm{~h}$. These glutaraldehyde modified electrodes were further modified with UBE2C antibody and BSA to fabricate the immunosensors. The immunosensors developed with 1 and 
$2.5 \%$ of glutaraldehyde gave a weak response towards recombinant UBE2C protein which may be due to the ineffective crosslinking of the antibody molecules. $4 \%$ and $5 \%$ glutaraldehyde concentrations provided a good immunosensor response. To avoid the use of high level of glutaraldehyde, $4 \%$ glutaraldehyde was chosen to fabricate the immunosensor. To optimise the amount of UBE2C antibody loaded on the electrode surface, 1,2 , and $3 \mu \mathrm{g} \mathrm{mL} \mathrm{m}^{-1}$ of anti-UBE2C were taken for immunosensor fabrication. The impedance responses for these concentrations were recorded. It was observed that the charge transfer resistance $\left(R_{\mathrm{ct}}\right)$ value increased with increase in antiUBE2C concentrations (Fig. S2 $\dagger$ ). As 2 and $3 \mu \mathrm{g} \mathrm{mL}{ }^{-1}$ are showing an almost similar response, therefore, $3 \mu \mathrm{g} \mathrm{mL}{ }^{-1}$ was taken as the optimum concentration for immunosensor fabrication.

\section{Electrochemical characterization of the fabricated immunosensor}

Scheme 1 represents the fabrication method of the immunosensor. CV was carried out to follow the stepwise fabrication procedure of the immunosensor. Fig. 2A shows the cyclic voltammograms of the electrodes at different stages of immunosensor fabrication. $\mathrm{CV}$ at the bare GCE shows a well defined quasi-reversible electrochemical response. In the present study, PANI is used as the immobilization matrix for the antibody because of its high conductivity, excellent biocompatibility and low cost. ${ }^{22}$ After the assembly of PANI film on the GCE surface (GCE/PANI), the CV curve changed drastically, and another oxidation peak at $0.56 \mathrm{~V}$ was observed. The considerable increase in the peak current of the redox probe is due to the increase in the electron transfer rate through the highly conductive PANI. However, post glutaraldehyde crosslinking (GCE/PANI/GLU), the peak currents decreased. The crosslinking and reduced porosity with glutaraldehyde may pose an obstruction to the diffusion of ferricyanide towards the electrode surface. Moreover, the aldehyde groups of the glutaraldehyde may hinder the electron transfer process. The incorporation of anti-UBE2C antibodies on the electrode surface (GCE/PANI/GLU/UBE2C$\mathrm{Ab}$ ) remarkably decreased the peak current which may be due to the blocking of ferrocyanide transport by nonconductive antibody molecules. Finally, when BSA was added (GCE/PANI/GLU/UBE2C-Ab/BSA), there was a muchdiminished ferricyanide response. The protein overcrowding may have jammed the remaining conductive ends on the electrode surface.

Fig. 2B shows the impedance spectra presented as Nyquist plots obtained on different modified electrodes in 0.1 M PBS (pH 7.4) with $5.0 \mathrm{mM}\left[\mathrm{K}_{3} \mathrm{Fe}(\mathrm{CN})_{6} / \mathrm{K}_{4} \mathrm{Fe}(\mathrm{CN})_{6}\right]$ and $0.1 \mathrm{M} \mathrm{KCl}$. In the impedance spectra, the diameter of the semicircle portion at higher frequencies represents the $R_{\mathrm{ct}}$ at the electrode surface. The value of the $R_{\mathrm{ct}}$ is indicative of the dielectric properties at the electrode/electrolyte interface. The variation in the $R_{\mathrm{ct}}$ was employed to further monitor the interfacial properties on the electrode surface during the stepwise assembly of the immunosensor. All the impedance spectra were fitted into Randles equivalent circuit (ESI Fig. S3, Table S1 $\dagger$ ). As expected, the results obtained by EIS are in agreement with those observed by $\mathrm{CV}$. The impedance spectra of the bare GCE consist of a small semicircle with a straight line, typical of a diffusional limiting step of the electrochemical process. The PANI modified GCE surface showed a very small $R_{\mathrm{ct}}$, owing to the accelerated electron transfer with highly conducting PANI film. When the PANI film was crosslinked with glutaraldehyde, the $R_{\mathrm{ct}}$ value
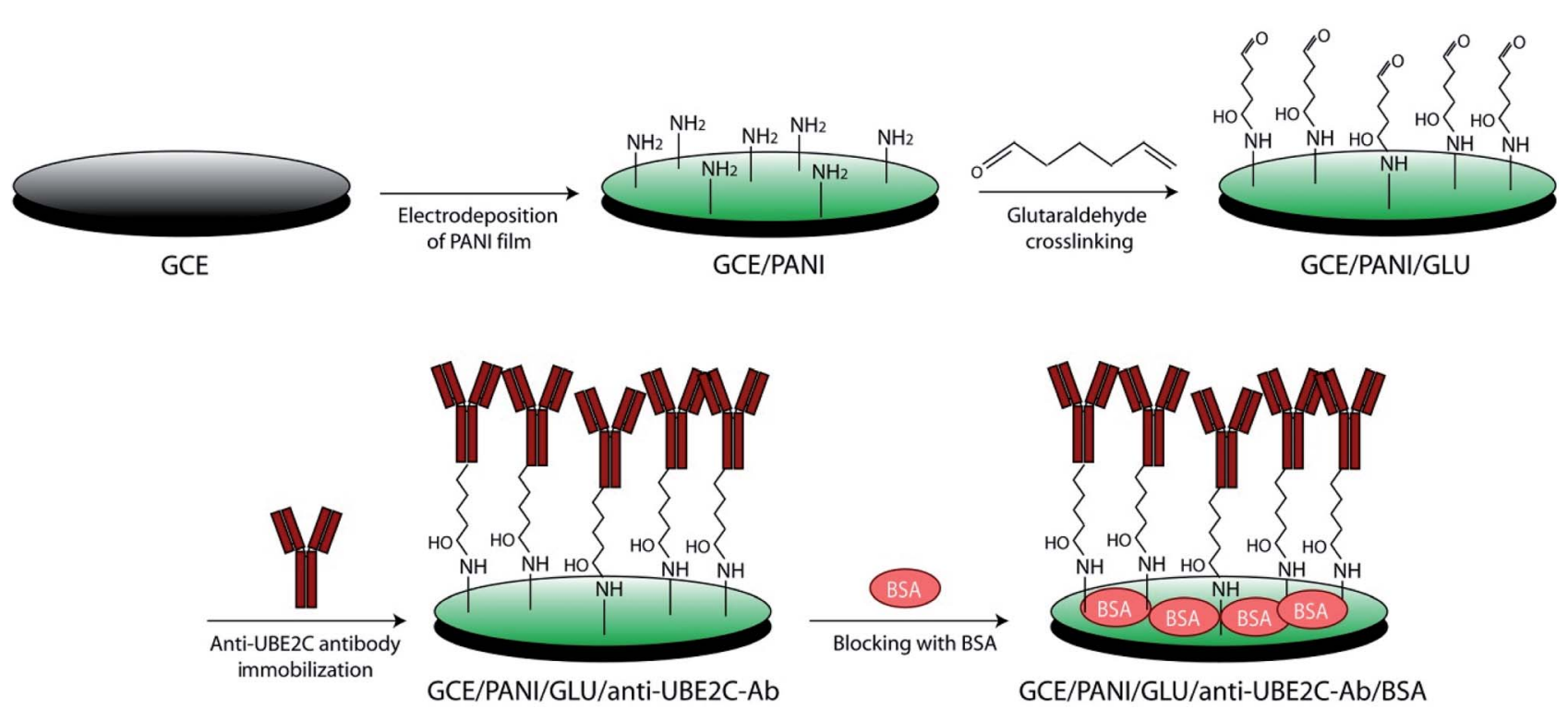

Scheme 1 Schematic representation of the immunosensor fabrication. PANI is electrodeposited on GCE (for better representation, only terminal primary amines of electrodeposited PANI are shown). Glutaraldehyde was used as a crosslinking agent to immobilize anti-UBE2C antibody on the electrode surface (for some fraction of the glutaraldehyde, both ends will be crosslinked to the surface amines). BSA was used as a blocking agent. 

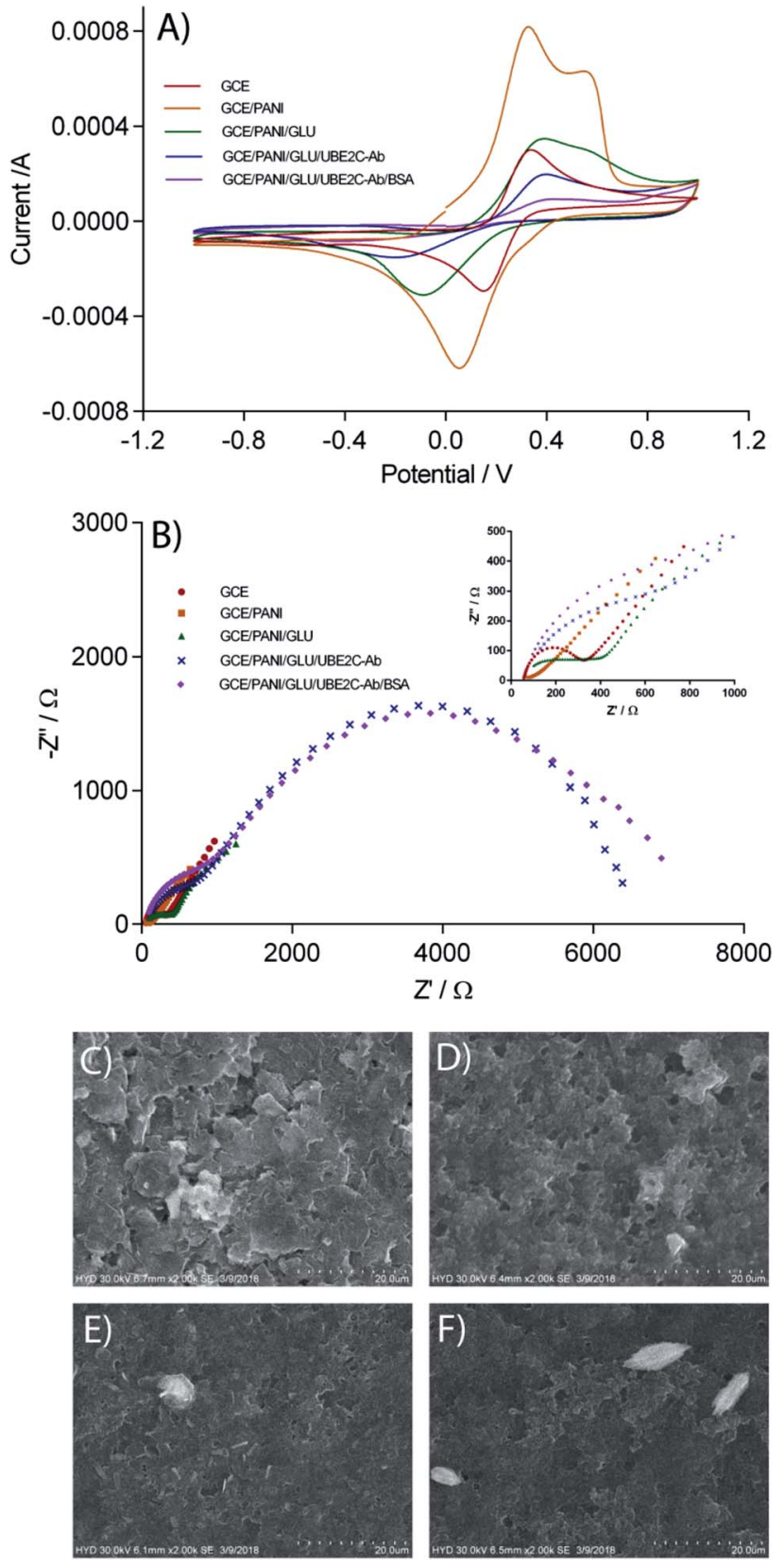

Fig. 2 Characterization of the UBE2C immunosensor. (A) Cyclic voltamograms of GCE, GCE/PANI, GCE/PANI/GLU, GCE/PANI/GLU/ UBE2C-Ab, and GCE/PANI/GLU/UBE2C-Ab/BSA electrodes in $0.1 \mathrm{M}$ PBS (pH 7.4) with $5.0 \mathrm{mM}\left[\mathrm{K}_{3} \mathrm{Fe}(\mathrm{CN})_{6} / \mathrm{K}_{4} \mathrm{Fe}(\mathrm{CN})_{6}\right]$ and $0.1 \mathrm{M} \mathrm{KCl}$. Scan rate: $100 \mathrm{mV} \mathrm{s}^{-1}$. (B) Electrochemical impedance spectra obtained at GCE, GCE/PANI, GCE/PANI/GLU, GCE/PANI/GLU/UBE2C-Ab, and GCE/PANI/GLU/UBE2C-Ab/BSA electrodes $0.1 \mathrm{M}$ PBS ( $\mathrm{pH} 7.4$ ) with $5.0 \mathrm{mM}\left[\mathrm{K}_{3} \mathrm{Fe}(\mathrm{CN})_{6} / \mathrm{K}_{4} \mathrm{Fe}(\mathrm{CN})_{6}\right]$ and $0.1 \mathrm{M} \mathrm{KCl}$. EIS measurements were carried out with an alternating wave of $10 \mathrm{mV}$ amplitude in the frequency range between 10000 and $0.05 \mathrm{~Hz}$. (B) inset: enlarged impedance spectra. (D-G) SEM images of different electrode surfaces obtained during the immunosensor fabrication. (C) CE, (D) CE/PANI, (E) CE/PANI/GLU, (F) CE/PANI/GLU/UBE2C-Ab (enlarged version of SEM is provided in ESI Fig. $S 4 \uparrow$ ).

increased back which is almost similar to bare GCE. Glutaraldehyde crosslinked PANI film maintained the conductivity of the GCE while providing biocompatible support for the antibody immobilization. As expected, a remarkable increase in the $R_{\mathrm{ct}}$ value was apparent after the assembly of the polyclonal rabbit anti-UBE2C antibody molecules. This point towards the obstruction of the electron transfer process at the electrode surface by the assembled antibody molecules. Consistent with the $\mathrm{CV}$ results, there was a further increase in semicircular diameter of the impedance spectrum when the blocking was done with BSA due to the formation of an additional barrier to the electron transfer process. The CV and EIS results are indicative of the successful fabrication of the immunosensor.

\section{Surface characteristics of the immunosensor}

The changes in the surface morphology of the electrode during the critical steps of immunosensor fabrication were examined using SEM. Fig. 2C illustrates the SEM image of the carbon electrode (CE). A likely granular morphology of the PANI ${ }^{25}$ can be observed in the SEM image of PANI modified electrode (Fig. 2D). The grainy surface of PANI augments the specific electroactive surface area of the electrode appropriate for superior antibody immobilization. Additionally, the porous networks of PANI may help in accelerated charge transfer kinetics at the immunosensor surface. The glutaraldehyde crosslinking did not affect the surface morphology of PANI (Fig. 2E). The glutaraldehyde crosslinked PANI provide wellorganized support for the immobilization of the polyclonal rabbit UBE2C antibody onto the electrode surface through the interaction between aldehyde groups of glutaraldehyde and the amine group of capture antibody. When anti-UBE2C antibody molecules were laid on the electrode surface, the granularity of the electrode surface thickened (Fig. 2F), indicative of the assembling of antibody molecules on the granular PANI surface. The SEM images signify the successful integration of the antibody molecules on the PANI over the electrode surface.

\section{Analytical performance of the fabricated immunosensor for the determination of UBE2C}

The fabricated immunosensor (GCE/PANI/GLU/UBE2C-Ab/BSA) was incubated with increasing concentrations of UBE2C

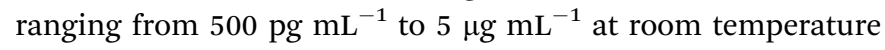
for $1 \mathrm{~h}$, to check its performance for detecting UBE2C. Fig. 3A shows the resulting impedance spectra. Quadruplicate $(n=4)$ analysis was performed at each concentration. After each detection of UBE2C protein, used electrodes were regenerated by incubation in a solution containing $6 \mathrm{mM} \mathrm{NaOH}$ and $0.6 \%$ ethanol for $5 \mathrm{~min}$ before washing with PBS three times. Fig. 3B represents a gradual increase in the $R_{\mathrm{ct}}$ values with increasing UBE2C concentration. As the number of immunocomplexes increased on the sensor surface, they increased the barrier for the electron transfer between $\left[\mathrm{Fe}(\mathrm{CN})_{6}\right]^{3-14-}$ and the electrode surface. However, at higher concentrations, the change in the $R_{\text {ct }}$ values is less steep because of the saturation of antibody molecules. A good linear correlation $\left(r^{2}=0.9914\right)$ was observed between $R_{\mathrm{ct}}$ and the logarithmic value of UBE2C concentration in a range of $500 \mathrm{pg} \mathrm{mL}^{-1}$ to $5 \mu \mathrm{g} \mathrm{mL} \mathrm{m}^{-1}(n=4)$ (Fig. 3B). The sensor response was highly precise, as indicated by the small 

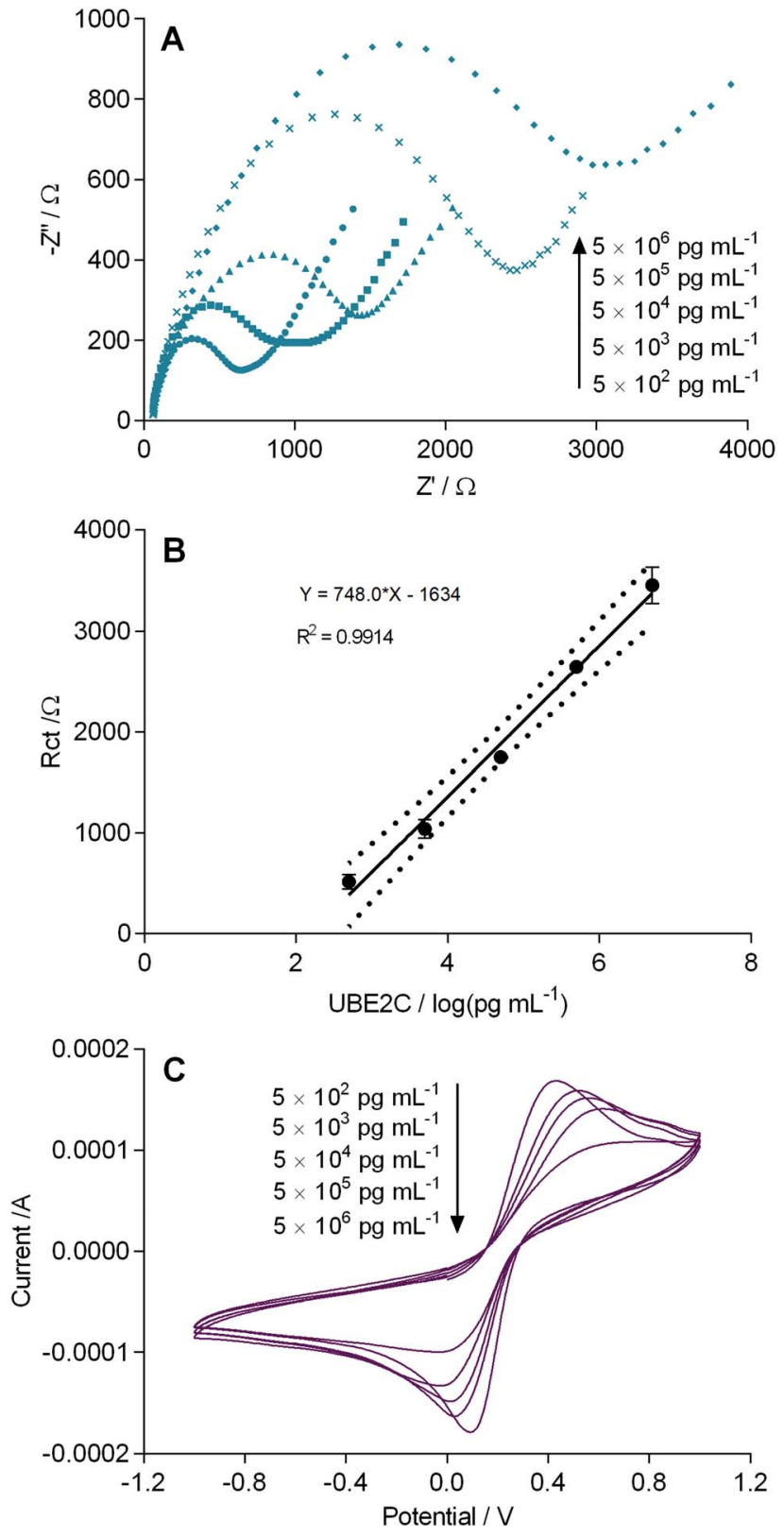

Fig. 3 (A) Electrochemical impedance spectra obtained after incubation of the immunosensor (GCE/PANI/GLU/UBE2C-Ab/BSA) with increasing concentrations of UBE2C. EIS measurements were carried out with an alternating wave of $10 \mathrm{mV}$ amplitude in the frequency range between 10000 and $0.05 \mathrm{~Hz}$ in $0.1 \mathrm{M} \mathrm{PBS}(\mathrm{pH} 7.4)$ with $5.0 \mathrm{mM}$ $\left[\mathrm{K}_{3} \mathrm{Fe}(\mathrm{CN})_{6} / \mathrm{K}_{4} \mathrm{Fe}(\mathrm{CN})_{6}\right]$ and $0.1 \mathrm{M} \mathrm{KCl}$. (B) Calibration plot of the immunosensor with increasing concentrations of UBE2C. Each datum point represents the average of the analysis of quadruplicate values ( $n$ $=4$ ). Dotted lines represents the 95\% confidence interval of each datum point. Error bars correspond to the standard deviation (SD) of four measurements $(n=4)$ under each condition. (C) Cyclic voltammograms obtained after incubation of the immunosensor (GCE/PANI/ GLU/UBE2C-Ab/BSA) with increasing concentrations of UBE2C. CV was carried out in $0.1 \mathrm{M}$ PBS $(\mathrm{pH} 7.4)$ with $5.0 \mathrm{mM}\left[\mathrm{K}_{3} \mathrm{Fe}(\mathrm{CN})_{6} /\right.$ $\mathrm{K}_{4} \mathrm{Fe}(\mathrm{CN})_{6}$ ] and $0.1 \mathrm{M} \mathrm{KCl}$. Scan rate: $100 \mathrm{mV} \mathrm{s}^{-1}$.

error bars. The CV results are in agreement with the impedance results where a decrease in the peak currents with increasing concentration of UBE2C can be observed (Fig. 3C). The LOD and the LOQ of the immunosensor were calculated from the expression $\mathrm{LOD}=(3 \times \mathrm{SD}) / m$ and $\mathrm{LOQ}=(10 \times \mathrm{SD}) / m$ (where $\mathrm{SD}$ is the estimated standard deviation from the points used to construct the calibration curve and $m$, its slope). ${ }^{26,27}$ The LOD and LOQ of the fabricated immunosensor were obtained as $7.907 \mathrm{pg} \mathrm{mL} \mathrm{mL}^{-1}$ and $26.356 \mathrm{pg} \mathrm{mL}^{-1}$ respectively. The detection limit obtained with the fabricated immunosensor was observed to be lower than the immunosensors reported for many other cancer biomarkers (ESI Table S2 $\dagger$ ). These results showed that the fabricated immunosensor has an acceptable analytical performance and is detectably responsive to UBE2C even in the low picomolar range which was not feasible with ELISA. The PANI film aided the electrochemical signal enhancement providing a lower detection limit of the immunosensor.

\section{Reproducibility and storage stability of the immunosensor}

The reproducibility of the fabricated GCE/PANI/GLU/UBE2C$\mathrm{Ab} / \mathrm{BSA}$ immunosensor was assessed in two ways. In the first instance, five different immunosensors prepared with the method developed here were subjected to $0.05 \mu \mathrm{g} \mathrm{mL}$ UBE2C solutions, and the impedance response $\left(R_{\mathrm{ct}}\right)$ were recorded. A relative standard deviation (RSD) value of $3.51 \%$ was obtained. Reproducibility was also evaluated by detecting $0.05 \mu \mathrm{g} \mathrm{mL}{ }^{-1}$ UBE2C successively five times using the same immunosensor. The immunosensor was regenerated between each analysis. In this case, the RSD was observed to be $3.11 \%$. The obtained RSD values in each case confirm an acceptable reproducibility of the proposed fabrication process of immunosensor and the electrochemical measurements. For investigating the storage stability of the fabricated immunosensor, a freshly prepared immunosensor was used to check its response against $0.05 \mu \mathrm{g} \mathrm{mL}^{-1} \mathrm{UBE} 2 \mathrm{C}$. This immunosensor was stored in PBS $(0.1 \mathrm{M}, \mathrm{pH} 7.4)$ at $4{ }^{\circ} \mathrm{C}$. The immunosensor retained $\sim 86 \%$ of its initial response after four weeks when again checked against $0.05 \mu \mathrm{g} \mathrm{mL} \mathrm{m}^{-1}$ UBE2C. Good operational and storage stability is attributed to the glutaraldehyde crosslinking of antibody molecules on the PANI surface which prevents the leakage of the antibody molecules from the electrode surface. Also the biocompatibility of PANI aided in better biorecognition phenomenon on the sensor surface.

\section{Real sample analysis with the developed immunosensor}

Higher expression of UBE2C draws a parallel with the progression of various human cancers including breast cancer. ${ }^{12}$ Western blot analysis confirmed the expression of UBE2C in MCF-7 cell line (Fig. 1C). The fabricated immunosensor was used to quantitatively analyze UBE2C in breast cancer cell line MCF-7. For this, the immunosensor was incubated with different dilutions of MCF-7 cell extract (1: 100 dilution, $1: 10$ dilution and crude extract) (in $0.1 \mathrm{M}$ PBS, $\mathrm{pH}$ 7.4) at room temperature for one hour and the immunosensor response was recorded. The concentration of UBE2C in these dilutions of MCF-7 cell extract was calculated from the calibration curve. The immunosensor was further incubated with $0.005,0.05$, and $0.5 \mu \mathrm{g} \mathrm{mL}{ }^{-1}$ recombinant 
Table 1 Determination of UBE2C spiked in MCF-7 cell extract with the immunosensor ${ }^{a}$

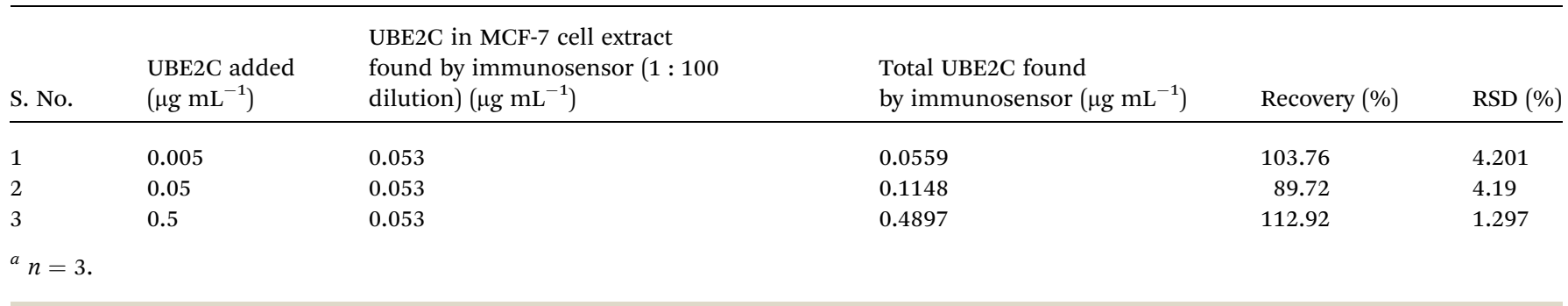

UBE2C spiked in 1 : 100 dilution of MCF-7 cell extract and the immunosensor response was recorded. The measured concentration of UBE2C in 1:100 dilution of MCF-7 cell extract before and after addition of recombinant UBE2C are shown in Table 1 . The UBE2C recoveries were obtained in the range of $89.72-112.92 \%$ and RSD was in the range of 1.29$4.20 \%$. The optimal recovery shows the negligible interference of the cell extract matrix on the performance of EIS based UBE2C immunosensor for the detection of UBE2C.

\section{Conclusion}

This study describes the integration of an EIS based immunosensor for direct quantification of UBE2C. The immunosensor was fabricated by immobilizing anti-UBE2C antibodies on the PANI-modified GCE surface through glutaraldehyde crosslinking. To the best of our knowledge, this is the first report on the development of immunosensor or biosensor for UBE2C, an important diagnostic and prognostic biomarker for breast cancer. We have used recombinant human UBE2C as the target protein. Owing to the high conductivity and biocompatibility of PANI, the proposed immunosensor exhibited outstanding analytical performance with a wide detection range of $500 \mathrm{pg} \mathrm{mL}^{-1}$ to $5 \mu \mathrm{g}$ $\mathrm{mL}^{-1}$, good reproducibility and storage stability. Due to the lower LOD of $7.907 \mathrm{pg} \mathrm{mL}^{-1}$, the developed immunosensor can detect UBE2C in the breast cancer cell MCF-7 extract with good selectivity, outperforming the conventional ELISA. Consequently, the proposed design of the immunosensor used here may be potentially applied for the detection of various other biomarkers in clinical diagnosis without the need for any sample pre-processing. Also, by coupling multiple antibodies and using the same design principle developed in this work, a multiplexed detection of appropriate breast cancer biomarkers is possible. Furthermore, due to its simple design, the immunosensor can be miniaturized for developing a point of care system during clinical monitoring of the disease progression.

\section{Author contributions}

VSPKSAJ and US have done the immunosensor fabrication. VSPKSAJ and ABD have carried out the recombinant protein expression and cell culture experiments. US and ABD conceived and designed the study. US wrote the manuscript with the help of VSPKSAJ and ABD.

\section{Conflicts of interest}

The authors declare that they have no conflict of interest.

\section{Acknowledgements}

We acknowledge the financial assistance from Science and Engineering Research Board (SERB), Department of Science and Technology (DST), Govt. of India. We also thank Osmania University, Hyderabad for providing the SEM facility.

\section{References}

1 C. Xie, C. Powell, M. Yao, J. Wu and Q. Dong, Int. J. Biochem. Cell Biol., 2014, 47, 113-117.

2 F. Stegmeier, M. Rape, V. M. Draviam, G. Nalepa, M. E. Sowa, X. L. Ang, E. R. McDonald 3rd, M. Z. Li, G. J. Hannon, P. K. Sorger, M. W. Kirschner, J. W. Harper and S. J. Elledge, Nature, 2007, 446, 876-881.

3 Z. Hao, H. Zhang and J. Cowell, Tumour Biol., 2012, 33, 723730.

4 L. Jiang, C. G. Huang, Y. C. Lu, C. Luo, G. H. Hu, H. M. Liu, J. X. Chen and H. X. Han, Brain Res., 2008, 1201, 161-166.

5 T. Rajkumar, K. Sabitha, N. Vijayalakshmi, S. Shirley, M. V. Bose, G. Gopal and G. Selvaluxmy, BMC Cancer, 2011, 11, 80.

6 T. Fujita, H. Ikeda, N. Taira, S. Hatoh, M. Naito and H. Doihara, BMC Cancer, 2009, 9, 87.

7 K. Ieta, E. Ojima, F. Tanaka, Y. Nakamura, N. Haraguchi, K. Mimori, H. Inoue, H. Kuwano and M. Mori, Int. J. Cancer, 2007, 121, 33-38.

8 L. Zhao, L. Jiang, L. Wang, J. He, H. Yu, G. Sun, J. Chen, Q. Xiu and B. Li, J. Cancer Res. Clin. Oncol., 2012, 138, 1951-1961.

9 S. Martinez-Canales, M. Lopez de Rodas, M. NunciaCantarero, R. Paez, E. Amir, B. Gyorffy, A. Pandiella, E. M. Galan-Moya and A. Ocana, Cancer Med., 2018, 7, 1896-1907.

10 S. Shuliang, C. Lei, J. Guangwu and L. Changjie, Oncol. Res., 2013, 21, 121-127.

11 M. T. Berlingieri, P. Pallante, A. Sboner, M. Barbareschi, M. Bianco, A. Ferraro, G. Mansueto, E. Borbone, E. Guerriero, G. Troncone and A. Fusco, Eur. J. Cancer, 2007, 43, 2729-2735.

12 C. H. Mo, L. Gao, X. F. Zhu, K. L. Wei, J. J. Zeng, G. Chen and Z. B. Feng, Cancer Cell Int., 2017, 17, 83. 
13 C. P. Chou, N. C. Huang, S. J. Jhuang, H. B. Pan, N. J. Peng, J. T. Cheng, C. F. Chen, J. J. Chen and T. H. Chang, PLoS One, 2014, 9, e93934.

14 A. Rawat, G. Gopal, G. Selvaluxmy and T. Rajkumar, Cell. Oncol., 2013, 36, 459-467.

15 T. Qin, G. Huang, L. Chi, S. Sui, C. Song, N. Li, S. Sun, M. Zhang, Z. Zhao, L. Li and M. Li, Biomed. Pharmacother., 2017, 95, 649-655.

16 D. Loussouarn, L. Campion, F. Leclair, M. Campone, C. Charbonnel, G. Ricolleau, W. Gouraud, R. Bataille and P. Jezequel, Br. J. Cancer, 2009, 101, 166-173.

17 S. F. Madden, C. Clarke, P. Gaule, S. T. Aherne, N. O'Donovan, M. Clynes, J. Crown and W. M. Gallagher, Breast Cancer Res., 2013, 15, R52.

18 J. Zhang, X. Liu, G. Yu, L. Liu, J. Wang, X. Chen, Y. Bian, Y. Ji, X. Zhou, Y. Chen, J. Ji, Z. Xiang, L. Guo, J. Fang, Y. Sun, H. Cao, Z. Zhu and Y. Yu, Front. Pharmacol., 2018, 9, 847.

19 R. Ma, X. Kang, G. Zhang, F. Fang, Y. Du and H. Lv, Oncol. Lett., 2016, 11, 2300-2304.
20 S. Bajaj, S. K. Alam, K. S. Roy, A. Datta, S. Nath and S. Roychoudhury, J. Biol. Chem., 2016, 291, 14231-14247.

21 A. Psyrri, K. T. Kalogeras, R. Kronenwett, R. M. Wirtz, A. Batistatou, E. Bournakis, E. Timotheadou, H. Gogas, G. Aravantinos, C. Christodoulou, T. Makatsoris, H. Linardou, D. Pectasides, N. Pavlidis, T. Economopoulos and G. Fountzilas, Ann. Oncol., 2012, 23, 1422-1427.

22 C. Dhand, M. Das, M. Datta and B. D. Malhotra, Biosens. Bioelectron., 2011, 26, 2811-2821.

23 J. Jin, X. Li, S. P. Gygi and J. W. Harper, Nature, 2007, 447, 1135-1138.

24 M. M. Bradford, Anal. Biochem., 1976, 72, 248-254.

25 J. Stejskal, I. Sapurina and M. Trchová, Prog. Polym. Sci., 2010, 35, 1420-1481.

26 L. Lu, R. Seenivasan, Y. C. Wang, J. H. Yu and S. Gunasekaran, Electrochim. Acta, 2016, 213, 89-97.

27 A. Shrivastava and V. B. Gupta, Chron. Young Sci., 2011, 2, 2125. 